\title{
Towards a Wellbeing-driven System Design for Intergenerational Collaborative Innovation: A Literature Review
}

\author{
Irawan Nurhas \\ Hochschule Ruhr West and \\ University of Jyväskylä \\ irawan.nurhas@hs- \\ ruhrwest.de
}

\author{
Stefan Geisler \\ Institute of Positive \\ Computing, Hochschule \\ Ruhr West \\ stefan.geisler@hs- \\ ruhrwest.de
}

\author{
Arto Ojala \\ Faculty of Information \\ Technology \\ University of Jyväskylä \\ arto.k.ojala@jyu.fi
}

\author{
Jan M. Pawlowski \\ Hochschule Ruhr West and \\ University of Jyväskylä \\ jan.pawlowski@hs- \\ ruhrwest.de
}

\begin{abstract}
Researchers have previously utilized the advantages of a design driven by well-being and intergenerational collaboration (IGC) for successful innovation. Unfortunately, scant information exists regarding barrier dimensions and correlated design solutions in the information systems (IS) domain, which can serve as a starting point for a design oriented toward well-being in an IGC system. Therefore, in this study, we applied the positive computing approach to guide our analysis in a systematic literature review and developed a framework oriented toward well-being for a system with a multi-generational team. Our study contributes to the IS community by providing five dimensions of barriers to IGC and the corresponding well-being determinants for positive system design. In addition, we propose further research directions to close the research gap based on the review outcomes.
\end{abstract}

\section{Introduction}

The importance of the global issue of well-being among the aging workforce for intergenerational innovation has been highlighted in several studies [21, 37, 39]. For instance, Forbes [20] noted that addressing intergenerational issues in diversity management is one of the key factors of successful global organizations and start-up innovation. In fact, cross-generational issues have become one of the key concerns of today's workforce, where employees of a single company might span up to four generations [20]. This study defines intergenerational innovation as a group of adults of more than one generation working together in the creative process to explore and apply valuable business ideas [4, 47]. The main goal of this paper is to understand the barriers and effects of intergenerational collaboration, particularly with regard to collaboration for global startups.
Although several studies in information systems (IS) propose the integration of well-being to improve IS design and support collaborative innovation processes $[13,44,49]$, a lack of in-depth understanding of barriers and how to embed well-being into the IS design of intergenerational collaboration (IGC) remains [47]. Furthermore, we found no publications providing information on dimension barriers to IGC or a framework that integrates well-being into IGC system design. Using the keyword "intergenerational" produced only 44 publications in the Association for Information Systems (AIS) digital library (based on an inquiry run on March 15, 2019). From those 44 publications, two papers related to well-being focused only on providing IS design for senior adults [13, 17], not for several generations in an IGC context.

Therefore, we aim to provide an overview and basis for a problem-based approach to system design, an analysis of barriers to ICG, and the correlated wellbeing determinants of intergenerational innovation. Based on the study objectives, we have conducted a two-stage literature review [27, 58] leading to a conceptual model for designing support systems in the context of intergenerational innovation. Systematically reviewing the literature $[27,58]$ on the barriers to IGC helped us to understand different types of barriers and design strategies correlated with technology-related well-being determinants in intergenerational innovation. For this purpose, we utilized the positive computing (PoCo) approach to the upcoming trends in the fields of human-computer interaction and IS design $[11,49]$.

The paper is structured in five additional sections: the theoretical foundation; the methodological section, comprising data collection and analysis; the results section, comprising barrier dimensions and the targeted well-being determinants; discussion; and finally, the conclusions of the study. 


\section{Foundation for the literature review}

\subsection{Intergenerational innovation}

As the knowledge-based society has grown, the ability to collaborate across continents and cultures has become an essential prerequisite for international companies. A global economy and demographic changes are also creating new opportunities to attract young talent from different countries to collaborate and improve global innovation processes. In addition, more experienced innovators can benefit from young trainees and actively participate in the global innovation process while improving their own well-being and social connectedness [63]. In terms of innovation processes, IGC can strengthen exploitation and commercialization processes by creating new opportunities [26].

We adopted the definition of generations based on Hilman [23]; the generational age difference is at least 20 years, which can be calculated from the difference in the median age of generations within one period of classification (e.g., the median age of Generation Y less the median age of Generation X). Therefore, we define younger adults as adults aged $18-30$ years and senior adults as 50 years and older.

The concept of intergenerational innovation is an intergenerational knowledge collaboration within the innovation process in which older and younger adults can exchange experience and knowledge related to the innovation process or to processes derived from ideation, design, or development. These exchanges are related to the commercialization of valuable ideas [13, 47]. On the one hand, senior adults are potential resources of innovation training and counseling for younger adults in a global environment. Conversely, barriers to intergenerational collaboration in digital learning seem to hamper collaboration [18]. We begin with three main processes of innovation to review the existing determinants of well-being to overcome the barriers to intergenerational collaboration in the innovation process.

\subsection{Barrier dimensions of collaboration}

The perception of IGC depends on age differences [55], but studies show that when conflicts do occur, they are due to differences in system interaction and operational styles rather than age differences [32]. If a system is designed for the younger generation, the developers may lose the older audience and vice versa. Age is not a factor in the success of interaction and learning [32], but is instead a demotivating element for both generations in using technology [33]. Barriers to intergenerational settings can demotivate the collaboration process. Several important barriers have already been studied by Edge [16] and Nurhas et al. [47], including, for instance, generational trust, lack of supportive environment, and different generational attributes.

We chose a classification of barrier dimensions from Adams [1] and Litz [36] because they cover a wide range of barriers to the creative collaboration process [1, 47]. The first dimension is the intellectual dimension, which is related to barriers caused by information, the beliefs of experts, and style. The second dimension is the perception dimension, which is caused by stereotyping. For example, perceptions of others based on gender, culture and physical characteristics. The third is the emotional dimension, which arises mainly from embarrassment, discomfort, or fear of failure. Last is the cultural and environmental dimension, which includes outside support and how to address a situation [1]. These barrier classifications can be used as a starting point to classify the dimension of the barriers to IGC in innovation process.

Therefore, based on the dimension of the barriers to creative collaboration [1], this literature review addresses the first guideline research question, "What barriers (and dimensions) exist in intergenerational collaboration?"

\subsection{Positive computing approach}

As technology provides new opportunities to mediate IGC, researchers have begun to study age differences in digital environments, with a focus on IGC in innovation processes [10, 23, 28, 47]. Focusing on the use of digital technology by the senior adults in IGC, Amaro et al. [2] found that senior adults are not technophobic and that they innovatively use IGC to maintain meaningful relations across borders [46].

Calvo and Peters [11] introduced the concept of PoCo, which promotes well-being determinants and enhances human potential through digital interaction. In this study, we used the PoCo approach as the basis of a design for a collaborative learning system between younger and older adults in the personal dimension. We used the PoCo approach because we believe that this approach will help us motivate older people to participate by giving them a meaningful task (for instance: sharing experiences, life wisdom or marketing strategies for specific target markets) and helping younger users by considering using the relatedness determinant to its full potential and thus becoming more successful. The PoCo process also requires the identification and consideration of barriers and challenges during technology design. Moreover, the provided well-being determinants of the PoCo approach 
focus on the personal level rather than on the organizational level. Those advantages of PoCo fit our research objective.

The PoCo approach is not limited to the user interface, but also covers the overall process to design of the IS [49]. PoCo can affect the entire process of system design, from initialization and user study to development and evaluation [49]. Calvo and Peters [11] introduced three classifications of determinants that can be used to improve well-being and can simultaneously be converted to technological design interventions. The groups of determinants consist of three groups of determinants [11]:

The first group of determinants is related to the self or the intrapersonal. This group primarily focuses on design features that support the personal interaction of the user with the system, including joyfulness, interest in exploring and learning, pride in achievements, selfviews, love or feeling safe, and close relationships), selfawareness, engagement, mindfulness, and resilience. The well-being driven technological interventions cover displeasing activities overlain with enjoyable interaction experiences.

The second group of determinants is related to the social or interpersonal. The determinants in this category provide interventions that support social connectedness among users and different social roles in the system. Determinants in this category include gratitude and empathy. The interventions include features to support expressions of appreciation; communication features aim to facilitate an expression of emotion using the narratives and graphics.

The last group of well-being determinants relates to the transcendent or extra-personal. This category emphasizes intervention for virtue or focusing on performing meaningful social actions. Calvo and Peters [11] categorized compassion and altruism in this group. Different types of technological interventions include a design for group empathy, technological features to minimize blame and judgment, and system development for inspiration that supports the ability to transform empathy into action.

Integrating well-being into a system's design process can occur on four levels of implementation [11]: The first level is no integration of well-being. The second level is preventive implementation (addressing barriers). The third level is an active approach (using well-being determinants for IS design), and last is the design of a system in which the overall goal is to foster targeted technology-oriented determinants of wellbeing and human potential. This study mainly focuses on the second and third levels.

Therefore, based on the PoCo approach, the wellbeing determinants can be used as keywords for content analysis. Hence, the second question for our review is
"Which well-being determinants are employed to foster IGC in innovation processes?"

\section{Methodology}

Our literature review follows the systematic process $[27,58]$, that described a method of reviewing relevant articles based on clearly formulated research questions, topics, or phenomena. An initial search resulted in 601 publications, and 57 publications were selected for analysis based on the study scope [7] and the inclusion and exclusion criteria. The overall structured process of the review is summarized in Figure 1.

\begin{tabular}{|c|}
\hline $\begin{array}{l}\text { Initial result: } 601 \text { publications } \\
\text { IEEE: } 64, \text { ACM: } 95 \text {, WoS: } 19 \text { SD: } 57, \text { TnD: } 366\end{array}$ \\
\hline remove duplications $\boldsymbol{V}$ \\
\hline $\begin{array}{l}\text { Title and abstract evaluation: } 170 \text { publications } \\
\text { IEEE: 61, ACM: 21, WoS: 4, SD: } 24 \text {, TnD: } 60\end{array}$ \\
\hline inclusion criteria $\boldsymbol{V}$ \\
\hline $\begin{array}{l}\text { Full-text evaluation: } 73 \text { publications } \\
\text { IEEE: 19, ACM: 10, WoS: } 2, \text { SD: 10, TnD: } 10\end{array}$ \\
\hline exclusion criteria $\boldsymbol{V}$ \\
\hline
\end{tabular}

Figure 1. Selection process of publications

\subsection{Data selection}

3.1.1. Keywords and Database. We employed a webbased automated search through digital libraries [27, 64]. for IGC-based studies published in scientific databases. The selection of the database was based on a proposed list of the top databases for software and technology engineering [64]. The selected databases were IEEE Xplore (IEEE), ACM Digital Library (ACM), Science Direct (SD), Taylor and Francis Online (TnD), and ISI Web of Sciences (WoS). The proposed databases included all reliable publications in a wide area of research from strong technically-oriented journals to more socio-technical fields such as IS journals and proceedings from the Association for Information Systems (AIS) Electronic Library. We believe that adding more databases would only provide duplicate results and increase the difficulty of validating the quality of publication processes.

We utilized a trusted database for the scholarly publication channel without limiting our scope to specific journals or proceedings because the topic is discussed in multidisciplinary research areas. To find correlated publications in selected databases, we applied two different groups of keywords; we applied a set of keywords on February 26, 2018, without limiting the time interval. The first group of keywords was for technology-specific databases. In the first category we 
found minimal sources if we specified the keywords; therefore, we introduced a more general search, related only to barriers to intergenerational collaboration and not specifically related to technology.

The keywords for our IEEE and ACM searches were ("intergenerational") OR ("intergenerational" $A N D$ ["barrier" OR "collaboration"]) OR ("intergenerational" AND ["barrier" OR "problem" OR "challenge" OR "GAP" OR "obstacle"]). Moreover, for non-technology focused databases, we detailed the keywords for designing a digital technology to support IGC in the workspace ("intergenerational" AND ["digital" OR "computer" OR "technology"] $A N D$ ["gap" OR "barrier"] AND ["workspace" OR "workplace”]).

3.1.2. Inclusion and exclusion criteria. A publication was selected as a source for the analytical process if the proposed inclusion criteria were met; a publication was removed from the reference list if it met the predefined exclusion criteria. Adhering to the research questions and guidelines for reviewing papers and scoping the study on IGC [7], the applied inclusion and exclusion criteria are presented in Table 1. For our study, we also excluded publications that focus only on collaboration between senior adults and children (age below 18 years) without clarifying the barriers and the potential research benefits for younger adults and senior adults.

\section{Table 1. Criteria for inclusion and exclusion}

\begin{tabular}{|l|l|}
\hline \multicolumn{1}{|c|}{ Inclusion } & \multicolumn{1}{|c|}{ Exclusion } \\
\hline - Peer-reviewed paper (journal & $\bullet$ Not written in \\
or conference proceeding) & English \\
- Explicit mention of & $\bullet$ No explicitly \\
intergenerational-related & stated barriers \\
terms in the abstract, title, or & to IGC \\
keywords & $\bullet$ Paper \\
- Collaboration between & incomplete or \\
generations related to the & research in \\
innovation process & progress. \\
\hline
\end{tabular}

\subsection{Data analysis}

To provide a design framework for IGC oriented toward well-being, we used the concept matrix [58] to create a matrix of barriers to IGC. We then synthesized the content of each selected publication, recorded the barriers, and combined the redundant barriers based on their associated verb and object. We first categorized the barriers into four barrier dimensions following the classification by Adams [1]. Any barrier that did not match one of the predefined classifications remained uncategorized.

We redefined the previous dimensions based on the barriers that corresponded to each; we described the perceptual dimension as thinking or opinion that focuses on the image of the other and renamed it an empathic dimension. We described the emotional dimension as a feeling that focuses on self-image. Both are related to the concept of self vs. other. We expanded the intellectual barriers to include technical and operational barriers since the identified barriers are correlated with knowledge regarding technological use and operational management.

In addition, some barriers in this dimension are also highly correlated with the new definition of the other two dimensions (point of view). Finally, the culturalenvironmental dimension was divided according to the rules and requirements, regardless of whether the barriers were organizational (officially written rules and requirements) or cultural (unofficially written). Furthermore, we recategorized the uncategorized barriers that corresponded to the newly defined dimensions. Possible disagreements regarding the categorization were resolved through discussions with the co-authors.

Although the barriers do not appear to be mutually exclusive, precise characteristics and definitions can be used to differentiate them and identify a tendency toward group-specific barriers. The proposed barrier dimensions occur in the interactions among user, system, and environment. Perceptual and emotional characteristics focus on the user's internal dimension, which is more intangible; the environmental or intangible external dimension of the user is cultural and institutional; and the system barrier is related to the technological and operational dimension or external tangible.

In the second stage of the analysis and review of the well-being determinants, we first determined the type of collaboration activity involved, such as ideation, design, and development or commercialization [4, 35]. Publications were grouped into collaborative and noncollaborative innovation activities. Of the collaborative innovation activities, we analyzed 23 (ideation: two publications; design and development: 12 publications; exploration: eight publications; and commercialization: one publication) to identify the well-being determinants of the PoCo approach to collaborative innovation activity. Five papers were removed because they did not mention well-being or correlate to the determinants of the PoCo approach, leaving only 18 publications.

We analyzed the remaining 18 publications looking for three main activities in the innovation process, using manual content analysis to find the determinants. We used the keywords based on the well-being determinants 
of PoCo approach and carefully read the selected papers to identify the corresponding determinants. Similarly, we can identify the correlated well-being determinants of collaborative innovation processes $[4,35]$.

\section{Findings}

Extracting the data based on year of publication of the reviewed papers (Figure 2, top) shows that researchers' interest in the IGC correspondent barriers has increased in the last five years. In 2016 and 2017, studies conducted on this topic more than doubled compared with the three previous years. Based on study origins, the global movement of the study of IGC includes every continent except Africa (Asia: 10\%; South America: 6\%; Australia/Oceania: 10\% Europe: 27\%; North America: 42\%; collaboration between North America and Europe: 5\%). The results of the analysis of the study origins parallel the growing number of individuals in the aging population on both continents [62].

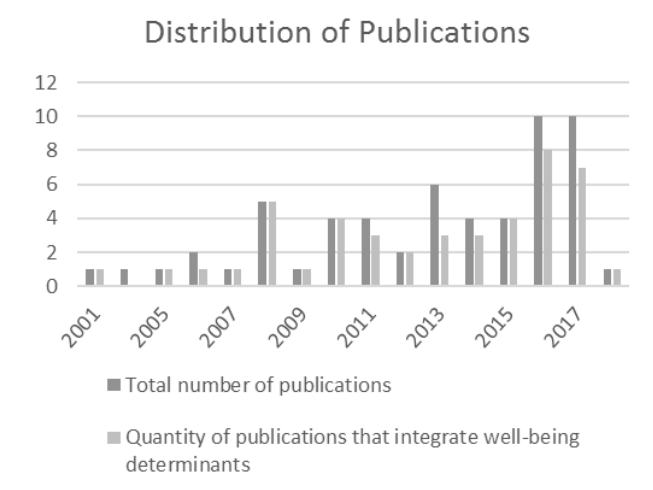

CONTEXT OF INDUSTRY

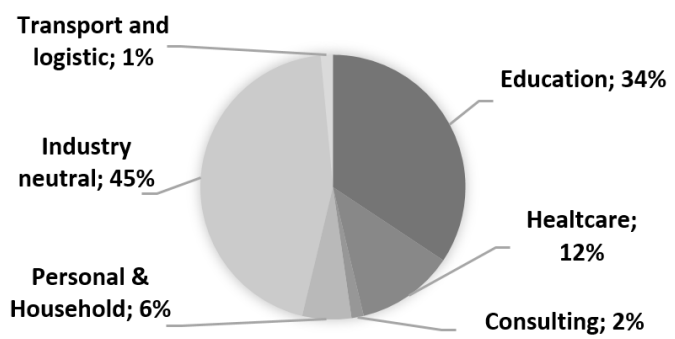

Figure 2. Mapping the Publications

Regarding the industry context within which the study was conducted (see figure 2, bottom), the study of IGC-related barriers usually focuses on neutral industries (or can be implemented across industries). However, education and healthcare are the two dominant industries in which barriers to IGC are commonly found. Interestingly, few studies focused on banking, retail, hospitality, or government.

\subsection{Barrier dimensions to intergenerational collaborative innovation}

The conceptual classification of the barrier dimensions for intergenerational innovation comprises five dimensions.

4.1.1. Emphatic/Perceptual dimension. We defined the empathic dimension as the negative viewpoint of a generation toward different generations. This strong negative viewpoint hinders IGC because of someone's experience in the past. Barriers related to perceptions of others include age discrimination [3, 34, 53], a different mindset $[16,53]$ and interests $[8,24]$, and generational resistance $[3,18,53]$. Moreover, a lack of understanding of IGC [5, 32], a lack of awareness of differences between generations $[16,18,50]$, a lack of empathy $[10$, 53], building interpersonal trust $[15,16]$ and a lack of respect $[10,53]$ are challenges to cross-generational collaboration.

4.1.2. Cultural dimension. The cultural dimension represents external environment-related barriers that concern informal codes and norms. One of the main issues of global collaboration is the substantial differences in cultural traditions compared with other generations $[8,12]$. Barriers also arise in this category because people are unaware that they can work with someone who is culturally different [43, 46]. Furthermore, other barriers in this dimension that can hinder IGC are a lack of social support $[8,12,16]$ and a lack of sensitivity to technological design that interferes with the cultural background of a particular generation $[6,46]$.

4.1.3. Emotional dimension. The emotional dimension is a collection of barriers associated with feelings and a negative self-view or egocentricity. These barriers are related to how one generation conceives of working with another generation. Barriers in this category are feeling underappreciated or unappreciated $[6,8,16,53]$ and feeling that others are slow to understand [10, 42]. Fear of technology $[5,8,9]$, functional limitations $[3,5$, 46], lack of motivation [5, 6] and feeling isolated [3] are barriers related to the emotional dimension.

4.1.4. Technological and operational dimension. The technological and operational dimension covers barriers related to knowledge and resources regarding technology and operational use. Barriers in this category include lack of independence [2, 28, 29], the high cost of technology investment $[3,8,15]$, the complexity of virtual presence management $[9,15]$, and generational differences in technological backgrounds $[6,8,10,12$, 15]. Other barriers are lack of joyful activities $[8,41]$ 
that can be integrated into real-life collaboration [3] the lack of technical training for digital collaboration [15], insufficient technological access [15] without a supportive technological environment $[31,57]$, and the complexity of technology $[9,15,22]$. In some cases, collaboration between the two generations could also be challenging because there is no right time for an appointment $[6,16,51,60]$ and the differences in routine patterns are unclear $[36,45]$.

4.1.5. Institutional dimension. The institutional dimension is defined as administrative barriers that focus on organized rules and requirements, including barriers to shared resources [45, 46, 57], geographical distance $[6,45]$ between cooperation partners and high market uncertainty in product markets [43] for innovation partnerships. Issues of data protection [15] and differences in educational levels [3, 8, 15] can complicate technology-mediated intergenerational collaborative innovation.

\subsection{Well-being determinants of IGC systems}

The collected publications did not explicitly mention the type of collaborative innovation activity within the context of IGC. Some publications addressed overall collaborative innovation activities [24, 36, 43], including exploration (ideation + design and development) and commercialization or market exploitation [35, 47]. Although IGC can strengthen innovation, we found only one publication [43] on IGCrelated barriers that supported collaboration in commercial activities. The correlated well-being determinants and associated collaborative innovation activities, with their sources, are presented in the following subsections.

4.2.1. Positive emotions of joy and playfulness in intergenerational knowledge exchanges. These positive emotions are feelings or expressions related to the emotional experience of pleasure that is integrated into IGC. One should feel joyful when using an IGC system. This determinant was identified in design and development $[12,52,54,56,59]$ and exploration [28, $36,38]$. The types of interventions related to joyfulness are the use of hybrid technology by combining the real and digital worlds in a collaborative activity [12, 54], the use of persuasive technology, and location-based gamification [28, 37, 38, 54, 56].

4.2.2. Positive emotions of interest in and exploration of a problem-based learning scenario. These feelings or expressions are related to the emotional experience of curiosity in the learning process that is integrated into
IGC. These feelings often occur in unpredictable scenarios. Twelve papers indicated the user's interest in and exploration of system design. The determinant was identified in the following collaborative innovation activities: ideation $[25,30]$, design and development [2, 12, 19, 29, 54, 56, 59], and exploration [28, 36, 38]. Competence development programs using blended learning for IGC were integrated $[12,36]$ to support the interests of collaborators. Instructional guidance for technological use, integrating hub actors, and gamification through assistive systems or robots are also utilized $[25,54]$.

4.2.3. Positive emotions of pride and achievement of collective goals. These are feelings or expressions related to the emotional experience of achieving meaningful goals, such as accomplishing a list. These emotions are found in exploration [28, 36, 38]. The types of interventions found in the literature are the digitalization of social presence, the use of persuasive technology [28, 38] and competence-based assessment [36].

4.2.4. Positive emotion of competence-based contentment and self-views. These emotions are feelings or expressions related to the emotional experience of high certainty and low effort based on self-evaluation. They are found in the collaborative innovation activities of ideation [25] and exploration $[28,40]$. The types of interventions in the literature are features to support competence exchange and competence building for IGC [25], the use of interactive storytelling, and scheduled IGC evaluation and assessment programs [28, 40]

4.2.5. Motivation and Engagement (ME). Motivation and engagement for the IGC community are a flow of experiences or the momentary condition that balances challenges and competence, stimulating eagerness, ownership, and possession. ME was found in 10 of 18 papers in the following collaborative innovation activities: ideation [30], design and development [2, 12, 19, 29, 52, 54, 56, 59, 61], and exploration/commercialization [28]. Gamification [54, 56], persuasive technology [28], self-assessment and evaluation instruments [29], competence acquisition through role-playing, and intergenerational community building [61] apply to this determinant.

4.2.6. Apprenticeship-based social relatedness (empathy, compassion, altruism). This determinant concerns the act of helping others. It provides functionality that can support social interaction and actualization to help others. Mentorship and companionship are examples of relatedness found in the 
collaborative innovation activity of exploration [24]. Some publications related the well-being determinant of "relatedness" to ME in the areas of ideation [30] and exploration $[10,38]$. IGC aims to improve relatedness between younger adults and senior adults through persuasive technology for the co-creation of innovative products [24], hybrid/blended learning [30], and location-based game [30], Workshop for competence development [30], digitize social presence and interaction [10].

\section{Discussion}

Determining barriers and correlated well-being determinants help to develop a conceptual framework for the positive design of IGC within the context of innovation activities. Within the preventative approach of PoCo [11], which minimizes factors that hinder IGC while interacting with technology, we identified five dimensional barriers. Those barrier dimensions apply generally to collaboration in a global context because the barriers were collected from various continents and include the cultural dimension.

Compared with previous dimensions $[1,36]$, in terms of IGC, our barrier dimensions support the current study on barriers to intergenerational innovation that contain specific dimensions for technological and operational knowledge [47]. These barrier dimensions also represent the nature of technology-mediated collaboration and the problem faced by different generations when interacting with technology. Moreover, we defined the empathic dimension as a barrier concerning interpersonal and extra-personal issues.

Regarding barriers in the PoCo framework, Calvo and Peters [11] proposed that gratitude and empathy may help connect interpersonal aspects and technology features. We found empathy, compassion, and altruism (ECA) within the context of collaborative innovation activities but not gratitude. ECA is associated with relatedness or social connectedness [11]. Therefore, we propose relatedness as the well-being goal of IGC or as the dedicated approach to IGC design oriented toward well-being. Barrier dimensions in IGC related to the empathic and the perceptual can be addressed through the use of robots, chatbots, or digital mediators that can mediate and reduce difficulties in communication and understanding one another $[25,54]$.

It seems that gratitude, as one of the strongest predictors of well-being [61], can be used as an alternative determinant of well-being in a dedicated approach to designing IGC systems. Supporting relatedness can be used in synchronous and asynchronous communication channels within the context of IGC learning [12, 38, 59]. Moreover, IGC can be designed to support coping abilities to transform empathy into action that can address judgment and blame [11]. A role play between generations in a local activity $[28,37,38,54,56]$ could increase connections and empathy among collaborators and address cultural, perceptual, and empathetic barrier dimensions.

We also found that compared with other well-being determinants, motivation and engagement are a primary focus in IGC publications (occurring in more than 55\% of selected papers). System designers should therefore consider interventions related to the determinant motivation and engagement to support IGC design. Moreover, it is essential to provide a common meaningful goal, empower creativity, and elicit appropriate feedback through virtual goods that can motivate [14] both the senior and younger adults.

We did not find any papers that mentioned "positive emotion." Instead, we noted that joy and interest were mentioned in $66 \%$ of IGC publications regarding innovation activities. Therefore, we included joy and interest as determinants that can be used to support IGC and proposed the positive emotions as a focus determinant of well-being in the active approach of PoCo. Moreover, the flow of experience can be integrated into positive emotions to cover pleasant activities such as serious games or gamification $[36,38$, $54,56]$.

Apparently, cultural, institutional, technical, and operational barriers are common in the design of IS [48, 58] and also appear in the IGC system. We included pride and contentment among the alternative determinants of an active approach to well-being [11]. Despite being two elements of positive emotion, they were rarely mentioned. Nevertheless, pride or achievement can be used in the exploration process. For instance, a system designer can use a progress bar, fixed action rewards, a leaderboard, and badges to facilitate both contentment and pride [14].

Related to institutional barriers, using the determinant of pride or achievement, the IGC system designer can integrate the competence-based selfassessment system into the matching process of the IGC system. IGC collaborators can assess their skills and achievements [29], which may overcome barriers, particularly in the institutional dimension. The selfassessment system can automatically match collaborators or help identify the right person with whom to collaborate. A hybrid technology [30] that combines tangible and intangible technologies can also lead to the delivery of a system that can be adapted according to users' physical and cognitive capabilities and preferences. 


\section{Conclusions}

Following the analysis, we built a conceptual model (figure 3) of an IGC system designed to address the barrier dimensions to IGC in the innovation process. We achieved this by integrating determinants that are classified into dedicated and active approaches of the PoCo framework.

Our findings reveal motivation, engagement, and positive emotion (interest and joy) and can be found in all three collaborative innovation activities. This finding indicates that these determinants play an essential role in IGC. Concerning motivation and engagement, tasks within innovation activities require specific competencies, e.g., problem-solving and creative thinking. The system can provide a flow of experiences to motivate both the senior and younger adults by providing a meaningful common goal for both generations, and the tasks in the IGC system must be suitable for the users' physical states as well as their physiological and cognitive abilities to avoid technostress.

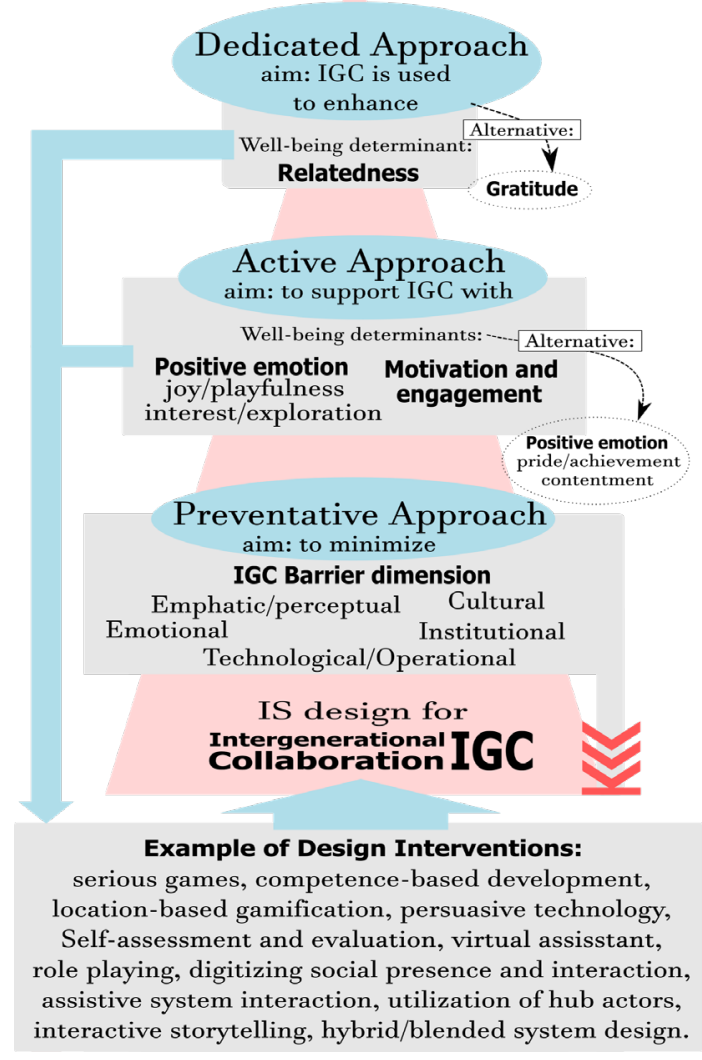

Figure 3. Wellbeing-oriented IS design for IGC

Interspersing the tasks with joyful experiences can help users overcome barriers (primarily in the empathic and emotional barriers dimension) and provide a flow of experience in technology-mediated IGC. We found that IGC is not only a global issue but is also attracting increasing attention from researchers across continents that can be useful in many industries, especially in the training and education industries.

Based on our review, we created a conceptual model that integrates the findings into a system design of innovation activities for IGC driven by well-being. Figure 3 depicts the conceptual model of a system design for intergenerational collaborative innovation that is oriented toward well-being. We hope that further studies on technology-mediated IGC will open up new possibilities to observe and develop the proposed framework.

The results of our review will also be used to develop further research questions that can be utilized to support IS research on a system design for intergenerational innovation oriented toward well-being (Table 2). The questions can be used as a baseline to address the gaps in recent IGC studies, and researchers can modify these questions to better fit their specific research problems. Moreover, a need remains to analyze the barriers based on geographic distribution and further attributes; such information can be used to design a global IGC system.

\section{Table 2: Proposed research questions}

\begin{tabular}{|c|c|}
\hline Topic & Proposed questions \\
\hline 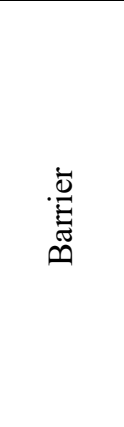 & $\begin{array}{l}\text { How does the barrier framework affect the } \\
\text { choice of technology and approaches in } \\
\text { intergenerational system design? } \\
\text { How do both generations perceive the } \\
\text { level of barriers to collaborative } \\
\text { innovation? } \\
\text { Which barriers do both generations } \\
\text { believe will have the most significant } \\
\text { impact on each of the more specific } \\
\text { collaborative innovation processes? }\end{array}$ \\
\hline 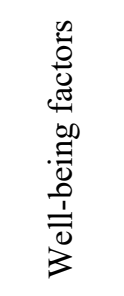 & $\begin{array}{l}\text { Which well-being determinants of PoCo } \\
\text { can promote IGC in the } \\
\text { commercialization process? } \\
\text { How and what type of human potential in } \\
\text { the global innovation process can be } \\
\text { supported by the dedicated design } \\
\text { approach of IGC? }\end{array}$ \\
\hline Method & $\begin{array}{l}\text { How can a well-being-oriented design } \\
\text { approach to an IGC system be evaluated? }\end{array}$ \\
\hline
\end{tabular}

\section{References}

[1] Adams, J.L., Conceptual blockbusting: A guide to better ideas, WW Norton \& Company, 1980.

[2] Amaro, A.C., L. Oliveira, and A.I. Veloso, "“Let's Build our Family Tree!": Grandparents and Grandchildren Using 
Tablets Together", Procedia Computer Science, 100, 2016, pp. 619-625.

[3] Anca, C.C., C. Stefan, and P. Lucia, eds., MyStory-digital kit for story telling as a therapy, IEEE, 2013.

[4] Andriopoulos, C. and M.W. Lewis, "Exploitationexploration tensions and organizational ambidexterity: Managing paradoxes of innovation", Organization science, 20(4), 2009, pp. 696-717.

[5] Atkinson, K., J. Barnes, J. Albee, P. Anttila, J. Haataja, K. Nanavati, K. Steelman, and C. Wallace, eds., Breaking barriers to digital literacy: An intergenerational socialcognitive approach, ACM, 2016.

[6] Binda, J., H. Park, J.M. Carroll, N. Cope, C.W.T. Yuan, and E.K. Choe, eds., Intergenerational sharing of health data among family members, ACM, 2017.

[7] Boger, J. and K. Mercer, "Technology for fostering intergenerational connectivity: scoping review protocol", Systematic reviews, 6(1), 2017, p. 250.

[8] Boulton-Lewis, G.M., L. Buys, J. Lovie-Kitchin, K. Barnett, and L.N. David, "Ageing, learning, and computer technology in Australia", Educational Gerontology, 33(3), 2007, pp. 253-270.

[9] Braun, M.T., "Obstacles to social networking website use among older adults", Computers in Human Behavior, 29(3), 2013, pp. 673-680.

[10] Brücknerová, K. and P. Novotný, "Intergenerational learning among teachers: Overt and covert forms of continuing professional development", Professional Development in Education, 43(3), 2016, pp. 397-415.

[11] Calvo, R.A. and D. Peters, Positive computing: Technology for wellbeing and human potential, MIT Press, 2014.

[12] Charles, J.M. and P.K. Charles, "Trends Toward the Future in Physical Activity Programming", Quest, 68(3), 2016, pp. 361-374.

[13] Choi, J., S. Kim, J.Y. Moon, J. Kang, I. Lee, and J. Kim, "Seek or Provide: Comparative Effects of Online Information Sharing on Seniors' Quality of Life", CAIS, 34, 2014, p. 27.

[14] Chou, Y.-k., "Actionable gamification", Beyond Points, Badges, and Leaderboards, 2015.

[15] Cresci, M.K., H.N. Yarandi, and R.W. Morrell, "Pro-Nets Versus No-Nets: Differences in Urban Older Adults' Predilections for Internet Use", Educational Gerontology, 36(6), 2010, pp. 500-520.

[16] Edge, K., "A review of the empirical generations at work research: Implications for school leaders and future research", School Leadership \& Management, 34(2), 2014, pp. 136-155.

[17] Erickson, L.B., ed., Social media, social capital, and seniors: The impact of Facebook on bonding and bridging social capital of individuals over 65, 2011.

[18] Fernández-de-Álava, M., C. Quesada-Pallarès, and M. García-Carmona, "Use of ICTs at work: An intergenerational analysis in Spain / Uso de las TIC en el puesto de trabajo: un análisis intergeneracional en España", Cultura y Educación, 29(1), 2017, pp. 120-150.
[19] Garzotto, F., ed., Broadening children's involvement as design partners: From technology to, ACM, 2008.

[20] https://i.forbesimg.com/forbesinsights/StudyPDFs/ Innovation_Through_Diversity.pdf, accessed 4-15-2018.

[21] Gordon, P.A., "Age diversity in the workplace", in Diversity and inclusion in the global workplace. 2018. Springer.

[22] Gutierrez, F.J., S.F. Ochoa, and J. Vassileva, eds., Identifying opportunities to support family caregiving in Chile, ACM, 2016.

[23] Hillman, D.R., "Understanding Multigenerational WorkValue Conflict Resolution", Journal of Workplace Behavioral Health, 29(3), 2014, pp. 240-257.

[24] Icenogle, R.S.H.M., "Preparing For An Age-diverse Workforce: Intergenerational Service-learning In Social Gerontology And Business Curricula", Educational Gerontology, 27(1), 2001, pp. 49-70.

[25] Jones, A., ed., Adult learning: The often overlooked aspect of technical training, ACM, 2003.

[26] Kawai, H., "Open Innovation University-Industry Collaboration: Student Idea Contests and Exit Strategy in Japan", JFMRA, 1(2), 2017, p. 31.

[27] Kitchenham, B., O.P. Brereton, D. Budgen, M. Turner, J. Bailey, and S. Linkman, "Systematic literature reviews in software engineering-a systematic literature review", Information and software technology, 51(1), 2009, pp. 7-15.

[28] Knight, L., L. Zollo, F. McArdle, T. Cumming, J. Bone, A. Ridgway, C. Peterken, and L. Li, "Drawing out critical thinking: Testing the methodological value of drawing collaboratively", European Early Childhood Education Research Journal, 24(2), 2016, pp. 320-337.

[29] Kokol, P. and G. Stiglic, eds., PRIMER ICT: A new blended learning paradigm for teaching ICT skills to older people, IEEE, 2011.

[30] Kopeć, W., K. Skorupska, A. Jaskulska, K. Abramczuk, R. Nielek, and A. Wierzbicki, eds., LivingLab PJAIT: Towards better urban participation of seniors, ACM, 2017.

[31] Kow, Y.M., J. Wen, and Y. Chen, eds., Designing online games for real-life relationships: Examining QQ farm in intergenerational play, ACM, 2012.

[32] Kurniawan, S.H., ed., Intergenerational learning through World of Warcraft, IEEE, 2008.

[33] Lebrón, J., K. Escalante, J. Coppola, and C. Gaur, eds., Activity tracker technologies for older adults: Successful adoption via intergenerational telehealth, IEEE, 2015.

[34] Lee, H.-C. and J.Y.-j. Hsu, eds., Picmemory: Enriching intergenerational family interaction and memory collection, ACM, 2016.

[35] Li, Y., W. Vanhaverbeke, and W. Schoenmakers, "Exploration and exploitation in innovation: Reframing the interpretation", Creativity and innovation management, 17(2), 2008, pp. 107-126.

[36] Litz, R.A., "Jamming across the generations: Creative intergenerational collaboration in the Marsalis family", Journal of Family Business Strategy, 1(4), 2010, pp. 185-199. 
[37] Litz, R.A. and R.F. Kleysen, "Your old men shall dream dreams, your young men shall see visions: Toward a theory of family firm innovation with help from the Brubeck family", Family Business Review, 14(4), 2001, pp. 335-351.

[38] Lynch, C., L.A. Stein, S. Grimshaw, E. Doyle, L. Camberg, and E. Ben-Ur, eds., The impacts of service learning on students and community members: Lessons from design projects for older adults, IEEE, 2014.

[39] Lyons, S. and L. Kuron, "Generational differences in the workplace: A review of the evidence and directions for future research", Journal of Organizational Behavior, 35(S1), 2014, S139-S157.

[40] McKay, E., ed., Human-computer interaction closes the digital divide: A multicultural, intergenerational ICT case study, Australian Computer Society, Inc, 2005.

[41] Mestheneos, E. and A. Withnall, "Ageing, learning and health: Making connections", International Journal of Lifelong Education, 35(5), 2016, pp. 522-536.

[42] Meza-Kubo, V., A.L. Moran, and M.D. Rodriguez, eds., Intergenerational communication systems in support for elder adults with cognitive decline, IEEE, 2009.

[43] Miller, D., L. Steier, and I. Le Breton-Miller, "Lost in time: Intergenerational succession, change, and failure in family business", Journal of business venturing, 18(4), 2003, pp. 513-531.

[44] Moqbel, M. and F.F.-H. Nah, "Enterprise social media use and impact on performance: The role of workplace integration and positive emotions", AIS Transactions on Human-Computer Interaction, 9(4), 2017, pp. 261-280.

[45] Muñoz, D., R. Cornejo, F.J. Gutierrez, J. Favela, S.F. Ochoa, and M. Tentori, "A social cloud-based tool to deal with time and media mismatch of intergenerational family communication", Future Generation Computer Systems, 53, 2015, pp. 140-151.

[46] Nedelcu, M., "Transnational grandparenting in the digital age: Mediated co-presence and childcare in the case of Romanian migrants in Switzerland and Canada", European journal of ageing, 14(4), 2017, pp. 375-383.

[47] Nurhas, I., B.R. Aditya, S. Geisler, A. Ojala, and J. Pawlowski, eds., We are "not" too (young/old) to collaborate: Prominent Key Barriers to Intergenerational Innovation, Association for Information Systems, 2019.

[48] Nurhas, I., T. de Fries, S. Geisler, and J. Pawlowski, eds., Positive Computing as Paradigm to Overcome Barriers to Global Co-authoring of Open Educational Resources, FRUCT Oy, 2018.

[49] Pawlowski, J.M., S.C. Eimler, M. Jansen, J. Stoffregen, S. Geisler, O. Koch, G. Müller, and U. Handmann, "Positive Computing", Business \& Information Systems Engineering, 57(6), 2015, pp. 405-408.

[50] Pilotte, M. and D. Evangelou, "Building bridgesidentifying generational communication characteristics to facilitate engineering collaboration and knowledge transfer across field-practicing engineers", Engineering Studies, 4(1), 2012, pp. 79-99.

[51] Ravazzani, S., S. Mormino, and M. Amicucci, eds., New Digital challenges for learning: Training on and by means of Web 2.0 with digital natives support, IEEE, 2013.

[52] Sandford, R., "Teachers as game designers: Using a game in formal learning in a Singapore primary school", Educational Media International, 51(1), 2014, pp. 66-78.

[53] Sellers, D.M., B.C. Bolender, and A.B. Crocker, "Beliefs about aging: Implications for future educational programming", Educational Gerontology, 36(10-11), 2010, pp. 1022-1042.

[54] Short, E.S., K. Swift-Spong, H. Shim, K.M. Wisniewski, D.K. Zak, S. Wu, E. Zelinski, and M.J. Matarić, eds., Understanding social interactions with socially assistive robotics in intergenerational family groups, IEEE, 2017.

[55] Skibiński, A., M. Sipa, and I. Gorzeń-Mitka, "An intergenerational cooperation in the organization-view from the age perspective", Procedia-Social and Behavioral Sciences, 235, 2016, pp. 412-419.

[56] Vetere, F., H. Davis, M.R. Gibbs, P. Francis, and S. Howard, eds., A magic box for understanding intergenerational play, ACM, 2006.

[57] Walsh, G., A. Druin, M.L. Guha, E. Bonsignore, E. Foss, J.C. Yip, E. Golub, T. Clegg, Q. Brown, and R. Brewer, eds., DisCo: A co-design online tool for asynchronous distributed child and adult design partners, ACM, 2012.

[58] Webster, J. and R.T. Watson, "Analyzing the past to prepare for the future: Writing a literature review", MIS quarterly, 2002, pp. xiii-xxiii.

[59] Wexler, S.S., L.J. Drury, J.F. Coppola, B.J. Tschinkel, and B.A. Thomas, eds., Service-learning computing courses assist with technology needs in community based organizations serving older adults, IEEE, 2011.

[60] Wilson, R.L., ed., De-Engineering intergenerational conflict: Suggestions for engineers resolving generational and interpersonal conflict, IEEE, 2008.

[61] Wood, A.M., S. Joseph, and J. Maltby, "Gratitude predicts psychological well-being above the Big Five facets", Personality and Individual differences, 46(4), 2009, pp. 443447.

[62] http://www.un.org/en/development/desa/population/ publications/pdf/ageing/WPA2015_Report.pdf, accessed 4$18-2018$.

[63] https://esa.un.org/unpd/wpp/Publications/Files/ WPP2017_Volume-II-Demographic-Profiles.pdf, accessed 4$17-2018$.

[64] Zhang, H. and M. Ali Babar, eds., On searching relevant studies in software engineering, British Informatics Society Ltd, 2010. 